\title{
ENTRE CLASICISMO Y MODERNIDAD. SOBRE EL SENTIDO DEL REALISMO POLÍTICO EN LA OBRA DE J. FREUND
}

\author{
Juan Carlos Valderrama Abenza \\ bttps://orcid.org/0000-0003-1643-1756 \\ Universidad CEU Cardenal Herrera, Valencia \\ https://doi.org/10.15304/ag.40.1.6529
}

\section{Resumen}

Frecuentemente se ha interpretado la filosofía política de Julien Freund como una lectura decisionista y polemocéntrica de lo político de fuertes ecos schmittianos. Sin entrar en el problema de sus raíces intelectuales, pretendo justificar en este artículo el sentido que asume en la obra del autor francés su adhesión a la tradición realista, distanciándose sin embargo de una interpretación tanto cratológica como nihilista de la política que tendiera a reducir los asuntos públicos al solo dominio estratégico de los medios. Entiendo, al contrario, que el realismo de Freund coincide con su perspectiva "mesocrática" o, si se prefiere, "liberal" en un sentido "árquico", no minarquista o neutralizador. Esto exige un cambio de enfoque en el estudio de su obra que evite fundamentalmente dos extremos: la reducción de lo político a la sola dialéctica del mando y la obediencia, a costa de la integración de todos sus factores, y la sobrevaloración del problema de los medios respecto de los fines.

Palabras clave: realismo político, maquiavelismo, decisionismo, liberalismo, mesocracia.

\begin{abstract}
Julien Freund's political philosophy has often been interpreted as a decisionist and polemocentric view of politics based on Schmittian echoes. Without entering into the problem of its intellectual roots, I intend to justify in this article the sense in which the French author assumes the realistic tradition of politics, distancing himself however from a cratological
\end{abstract}

Recibido: 14/01/2020. Aceptado: 30/06/2020. 
and a nihilistic interpretation of politics, which tends to reduce public affairs to the strategic control over means. I understand, in contrast, that Freund's realism coincides with his "mesocratic" or "liberal" perspective in an "archic" sense, not minarchist or neutralizing. This requires a change of approach in the study of Freund's work that fundamentally avoids two extremes: the reduction of political to the sole dialectic of command and obedience in detriment to the integrity of all its factors, and the overvaluation of means in relation to the goals of political activity.

Keywords: political realism, Machiavellianism, decisionism, liberalism, mesocracy.

\section{Sentido de lo político y realismo}

"Il y a une essence du politique". Así arrancaba Freund L'essence du politique (1965), su obra cumbre: hay una esencia de lo político. Eso significa, sigue diciendo, que la organización social responde a ciertas constantes básicas, "inmutables [...], independientes de las variaciones históricas, de las contingencias espaciales y temporales, de los regímenes y sistemas políticos" ${ }^{1}$, y que son en su conjunto regla y principio para el obrar concreto. No es solo que tengamos que habérnoslas con tener-que-ser políticos, como decía entre nosotros F. J. Conde ${ }^{2}$; es que serlo, en realidad, es el primero de los modos — "máximo" o "básico", según se mire— de formalización de la vida social, a la que de hecho la política confiere actualidad y cuyo contenido además fija en el tiempo.

Base irrenunciable para la inteligencia política tanto del hombre de acción como de quien pudiera rondarle sin otro interés que comprenderlo, este empeño por la rehabilitación del sentido (de lo) político impone también su método, una de esas "formas-límite del pensamiento político" que a juicio de Molina Cano es el realismo ${ }^{3}$, cuya entraña resumió Freund en un plástico aforismo: "saber prever lo peor y mostrarse capaz de impedir que llegue" ${ }^{4}$. Es la "imaginación del desastre" que dice también Molina ${ }^{5}$,

${ }^{1}$ J. Freund, L'essence du politique, París, Dalloz, 2004 (1ª: 1965), p. 1.

${ }^{2}$ F. J. Conde, El hombre, animal político, Madrid, Encuentro, 2011, p. 63.

${ }^{3}$ J. Molina, "Sobre las formas límite del pensamiento político", en L. Bueno Ochoa (coord.), Ismos y Política. Diálogos con Dalmacio Negro, Madrid, Universidad Complutense, 2013, p. 139; "El realismo, una forma límite del pensamiento político", en A. Campi $\&$ S. de Luca (comps.), Il realismo politico. Figure, concetti, prospettive di ricerca, Soveria Mannelli, Rubbettino, 2014, pp. 81-99, p. 99.

${ }^{4}$ J. Freund, Sociologie du conflit, París, P.U.F., 1983, p. 363.

5 J. Molina, J., "Realismo político y crítica de las religiones seculares en Raymond Aron", en M. Herrero (ed.), Religion and the Political, Hildesheim, Olms Verlag, 2012, p. 250; "Julien Freund o la imaginación del desastre", Nueva revista de política, cultura y 
principio inexcusable en una "moral de la política" ante la que con toda seguridad se irritan los partidarios de una "política moral" de hechuras ideológicas ${ }^{6}$.

Antes perspectiva que doctrina ${ }^{7}$, el realismo se opone a esta suerte de hipermoralización del utopismo ${ }^{8}$ y al pensamiento mágico de las ideologías que, so capa de enderezar la política a fines presuntamente humanizantes, liberándola por fin de su "grandeza sombría", acaba por entregarla a objetivos no siempre puros que arruinan a un mismo tiempo, confundiéndolas, política y moral ${ }^{9}$. El poder suele sacar provecho del entusiasmo que provoca con su retórica grandilocuente sobre las aspiraciones humanas más profundas ${ }^{10}$. Pocos siglos habrán sido de ello tan elocuentes como el nuestro, pasto fecundo de maquiavélicos de toda especie dados a esconder baja soflamas salvíficas y una constante exaltación de sentimientos nobilísimos lo que en realidad no era más desde el principio que simple y llanamente pasión por el poder. Aquí el sentido político se opone a lo impolítico ${ }^{11}$ e incluso más aún, lo antipolítico, que hace de la política algo no solo reemplazable por la moral, la técnica o la racionalidad jurídica, sino algo en realidad superfluo, víctima de lo que llamaba Jouvenel el "mito de la solución" de los problemas políticos sin amigos ni enemigos, o sea, sin política, y lógicamente también, sin decisión ${ }^{12}$.

arte 158, 2016, p. 231 ss; C. Gambescia, Liberalismo triste. Un recorrido de Burke a Berlin, Madrid, Encuentro, 2015, p. 10.

${ }^{6}$ Cf. J. Freund, "La surenchère morale en politique", Actions et recherches sociales. Revue interuniversitaire de sciences et pratiques sociales 28, 1987, pp. 45-62; "La politique politique", Tijdschift voor de studie van de verlichtine en van het Vrije Denken 16, 1988, pp. 197-212; Philosophie philosophique, París, La Découverte, 1990, p. 25 ss.

${ }^{7}$ Cf. A. Campi, "Raymond Aron y la tradición del realismo político", en J. Ma Lassalle (coord.), Raymond Aron. Un liberal resistente, FAES, Madrid, 2005, p. 72-73; Oro Tapia, L. R., El Concepto de Realismo Político, Santiago de Chile, Ril Edits., 2013.

${ }^{8}$ Cf. M. Weyemberg, Entre politique et technique: aspects de l'utopisme contemporain, París, Vrin, 1991, p. 91 ss.

${ }^{9}$ Cf. Sociologie du conflit, op. cit., p. 362; L'essence du politique, op. cit., p. 125.

${ }^{10}$ Cf. L'essence du politique, op. cit., p. 702.

11 “J'entends par impolitique la conduite pseudeo-politique qui offense l'esprit et le rôle de la politique [...] qui exerce consciemment ou non son action en blessant l'esprit de la politique ou en violant les raisons normatives et constitutives de l'activité spécifique qu'est la politique. Elle en déforme par ignorance ou incompétence sa finalité, ou bien elle l'outrage par le recours à des moyens abominables ou disproportionnés, ou encore elle se dérobe à la responsabilité des conséquences des décisions ou enfin elle manque de clairvoyance par parti-pris dans l'appréciation des situations", "La politique politique”, op. cit., p. 197, 209.

${ }_{12}$ B. de Jouvenel, Teoría pura de la política, Madrid, Revista de Occidente, 1965, pp. 260-269. Vid. J. Freund, Politique et impolitique, París, Sirey, 1987, pp. 49-59, 71-83; L'essence du politique, op. cit., p. 120 ss. 
Afirmar por el contrario "la política tal y como ella es" ${ }^{13}$, en su sentido específico - "la politique politique"-, obliga a socavar los prejuicios dominantes en tres tipos de hombre al mismo tiempo: 1.- el irenismo de quien cree factible una sociedad sin enemigos, como si los conflictos políticos, residuo de otras épocas, pudiera superarlos el progreso moral que nos promete el caminar incesante de la razón; 2.- el racionalismo, a su vez, de quien inmola la política a los criterios de otras instancias como garantía de su neutralidad, especialmente en sus versiones tecno y burocráticas; y 3.- el fetichismo de cuantos hacen de ella una herramienta escatológica al servicio de fines últimos cuyo cumplimiento constantemente se aplaza a un tiempo siempre necesariamente por llegar ${ }^{14}$.

De todos modos, renunciar a la utopía no implica en contrapartida rendirse a la ocasión, como si no le quedaran más que las imposiciones del presente a quien recelase de los encantos del pensamiento mágico. Hay junto a la realidad que se nos impone todo un vasto horizonte al que se abre la acción, y es el de lo posible. No solo en el sentido de lo que pueda pasar, que es algo de lo que políticamente es preciso hacerse cargo, sino también en el de lo que pudiera hacerse. "Hay que atenerse a los hechos", dice el realista, pero eso no supone desertar de la esperanza. De la estructura de los hechos forma parte tanto aquello que ya son como lo que pueden ser, tratándose de fenómenos humanos y no pura fatalidad. Así que abrirse a lo posible es atenerse a los hechos también. Lo contrario es solo una caricatura de realismo: es simple cinismo. Tener sentido de la realidad es reconocer sus límites, pero sus posibilidades también. Se lo declaraba Freund a un joven Xavier Cheneseau en una entrevista de 1990: "La esperanza, que es algo consustancial a la vida, es lo único que permite afrontar los posibles inconvenientes de estos turbios periodos de transición. Si todo fuese incierto respecto al porvenir, habría que abandonar toda esperanza, como en el infierno de Dante. Quien espera no se siente nunca abandonado; sigue siendo capaz de imaginar y anticipar, a la luz del pasado, perspectivas que van más allá de la lógica teórica” ${ }^{15}$.

Ese sería en realidad uno de los grandes méritos de quienes de modos muy distintos se han ido adscribiendo, como Freund mismo, al punto de vista histórico maquiaveliano: advertir además de los límites, las posibilidades que se le abren a la acción política en el interior de su campo, y no

\footnotetext{
${ }^{13} \mathrm{~J}$. Freund, La aventura de lo político, Madrid, Encuentro, 2019, p. 35.

${ }^{14}$ Ibidem, pp. 64-66.

${ }^{15}$ J. Freund, "Entretien avec Julien Freund", Vouloir 1990, p. 10.
} 
mediante su subordinación a una u otra medida diferente, fuese ésta jurídica, económica, técnica o de cualquier otro género. Solo dotado de auténtico sentido político puede uno contrarrestar la lectura maquiavélica —que no maquiaveliana - del poder. La diferencia era crucial para Freund ${ }^{16}$. Para ser maquiavélico basta merodear el poder; el maquiaveliano, en cambio, busca algo distinto: ir más allá de él — "en dehors du pouvoir"- como un observador atento y al mismo tiempo prudente de la práctica real de la política, a caballo permanentemente entre la perspectiva desinteresada del espectador y la pasión del hombre de gobierno ${ }^{17}$. Por eso, dice Freund, resulta tan "difícil ser al mismo tiempo maquiaveliano y consejero de príncipes, aunque tal cosa se produzca" ${ }^{18}$ : se necesita distancia.

\section{Desengaños de un hombre de acción}

Desconfiado ante las construcciones puramente intelectuales, el realismo de Freund fue más que puramente metodológico. Fue un punto de vista cuajado antes en el orden de la acción que en el de sus explicaciones ${ }^{19}$, el fruto granado de un buen manojo de desengaños sufridos durante su vincu-

16 "J'évoquerai une fois de plus la remarque pertinente de C. Schmitt: si Machiavel avait été machiavélique et non machiavélien il n'aurait pas écrit Le Prince, mais une quelconque Politique morale pour mieux duper son monde. On ne lui a guère pardonné cette lucidité. Apportons encore deux précisions concomitantes. D'une part, pour être machiavélique il importe d'avoir une collusion quelconque avec le pouvoir, soit pour le conquérir, soit pour le conserver, tandis que pour être machiavélien il faut se situer en dehors du pouvoir en tant qu'observateur aussi clairvoyant que possible de la pratique effective de la politique. Il est difficile d'être en même temps machiavélien et conseiller du prince, bien que cela puisse arriver", J. Freund, "La surenchère morale en politique”, op. cit., p. 46. Cf. C. Schmitt, El concepto de lo político, Madrid, Alianza, 2019, p. 94; Diálogo sobre el poder y el acceso al poderoso, Buenos Aires, F.C.E., 2010, p. 53.

${ }^{17}$ P.-P. Portinaro, El realismo político, Buenos Aires, Nueva Visión, 2007, p. 25.

${ }^{18} \mathrm{~J}$. Freund, "La surenchère morale en politique", op. cit., p. 46.

${ }^{19}$ Es lo que agudamente observa Campi, cómo en efecto "il realista viene dunque prima del realismo; lo studioso, con il suo personale modo di atteggiarsi dinnanzi al mondo, viene prima della corrente o dottrina all'interno della quale si riconosce o che contribuisce ad alimentare. Da un modo d'essere e da una predisposizione mentale, che obviamente possono anche essere il frutto, maturato nel corso del tempo, di letture, esperienze e suggestioni intellettuali, derivano dunque un metodo di studio, un approccio analitico e una chiave di interpretazione", A. Campi, "Le radici psicologiche del realismo", en A. Campi \& S. de Luca (comps.), Il realismo politico. Figure, concetti, prospettive di ricerca, op. cit., p. 699. Encontrará el lector en ese capítulo un mapa magníficamente definido de los resortes psicológicos, premisas metafísicas y certidumbres prácticas que cristalizan comúnmente en ese habitus realista. 
lación con los grupos de izquierda en los procesos de Résistance y Libération que decidieron el rumbo de la política francesa entre los años 1940 y 1946. Hecho prisionero en junio de 1940 por la muerte accidental de un motorista alemán en Henridorff ${ }^{20}$, Freund dio comienzo entonces a una intensa militancia política que le llevó a incorporarse en los grupos de resistencia de Libération Sud y Combat. Luego vendría un largo peregrinaje por centros de internamiento al que pondría fin con su huida de Sisteron (1944). Antes fueron los campos de Lyon, Saint-Paul d'Eyjaux, la prisión central de Eysses en Villeneuve-sur-Lot... En todo este tiempo, recluido el cuerpo, su inteligencia se evadía soñando con la transformación de Francia en encendidos debates con sus compañeros. "Teníamos ocasión-recordaba- de reconstruir intelectualmente la sociedad, sin más obstáculo que los muros de la prisión y las alambradas del campo, al abrigo de cualquier contestación. [...] Bastaba imaginar lo que podía parecer teóricamente mejor, al margen de toda experiencia directa y concreta, para incluirlo en nuestros proyectos" 21 .

Todo aquel formidable edificio de una política imaginada al margen de los imperativos de la acción, estaba llamado a venirse abajo al descubrir de pronto cuál suele ser en el fondo el auténtico motor de la pasión política. En su evasión de Sisteron, Freund se cruzó con el maquis de los FrancTireurs et Partisans Français (F.T.P.F.), integrados desde hacía unos meses en las Forces Françaises de l'Intérieur (F.F.I.), y cuyas tensiones internas iba a tener ocasión de presenciar enseguida, algunas de forma especialmente dramática ${ }^{22}$. Vino a darse de bruces con la piedra de toque de la experiencia política, oculta normalmente bajo buenas intenciones que, aunque existan, suelen ser secundarias en política: "la passion du pouvoir" "23. No pues la generosidad de las ideas. Hoy asistimos, en cambio, dice, a una suerte de fetichismo moral que nos hace creer "que el orden social no se puede conservar sólidamente más que si tiene por fundamento la verdad, la justicia, la igualdad y la armonía universal". ¿El resultado? Que "pensadores políticos como Maquiavelo o Hobbes, que vieron en la potencia el elemento especifico de lo político tengan muy mala prensa, y no así Platón, Rousseau o Marx, defensores de una politica basada en la verdad, la justicia y la igualdad"24.

20 J. Freund, "Chapelet de souvenirs", Bulletin de la Faculté des Lettres de Strasbourg 47, 1968, p. 10.

${ }^{21}$ J. Freund, "Ébauche d'une autobiographie intellectuelle", Revue européenne des sciences sociales 54-55, 1981, p. 15.

${ }^{22}$ Como botón de muestra, vid. J. Freund, La aventura de lo político, op. cit., p. 31 ss.

${ }^{23}$ J. Freund, "La passion de la politique", Foi et Vie 61/2, 1962, p. 48.

${ }^{24}$ Ibidem, pp. 53-54. 
La llegada de la paz ni mucho menos enfrió el clima de hostilidad de aquellos tiempos de guerra, que se prolongó bajo nuevas formas. Desplazándose a las entrañas del movimiento de Liberación, el conflicto, ahora esencialmente ideológico, devino un problema de política interior. Freund, harto de la mezquindad de muchos de los comportamientos de entonces, iría desembarazándose poco a poco de todos sus compromisos, embarcándose en un largo proceso de depuración intelectual de aquel cúmulo de decepciones del que L'essence du politique constituiría casi terapéuticamente, antes que el resultado, la forma misma de su superación.

El desconcierto ante los acontecimientos de aquellos años fue derribando, pieza a pieza, los esquemas que hasta el momento habían allanado su acceso a lo político. Más escabroso era el paisaje que se le presentaba ahora, en que se le imponía cada vez con más fuerza una tremenda evidencia: "pas de politique sans ennemi", no hay política sin enemigo. Con harta frecuencia la lucidez es hija de la confusión o de la decepción en el hombre de acción. Una muestra: él, que durante su militancia en Combat incluso había participado en varias acciones terroristas ${ }^{25}$, acabaría convirtiéndose en un objetivo para los comunistas, que atentaron contra él en Sarrebourg.

Esta evidencia, que conmovió completamente la visión de la política que había mantenido hasta el momento, le permitió también tomar conciencia de la naturaleza política del liberalismo que por aquellos mismos años le llegaba de mano de R. Aron, uno de los “dos grandes maestros", junto a Carl Schmitt, con quienes se declaró siempre en débito ${ }^{26}$. El conflicto, en efecto, y aún más la guerra, representa "uno de los obstáculos que ponen en cuestión la validez general del pensamiento liberal" 27 , ya que "pensar la

${ }^{25}$ Abogaba él mismo por su condición de terrorista ocasional siempre que debía, para escándalo de quienes pretendían evadir la responsabilidad sobre sus propios actos escudándose en el irenismo de sus posicionamientos ideológicos. Es un capítulo de especial interés del "Estudio Introductorio" de J. Molina a la nueva edición española de La esencia de lo político, Madrid, C.E.C., 2018 (\$\$\$3-4), a partir de datos históricos y relatos poco conocidos, incluso inéditos. Muy interesante sobre su actividad de resistente también C. Dirwimmer, "Julien Freund, étudiant et résistant", Annuaire de la Société d'Histoire du Val de Villé 1995, pp. 127-140.

${ }^{26} \mathrm{~J}$. Freund, L'essence du politique, op. cit., p. 6.

${ }^{27}$ J. Freund, Politique et impolitique, op. cit., p. 140. Justamente por eso, provocado por el impacto sobre Freund de las categorías schmittianas, D. Steinmetz-Jenkins ve problemático su encaje en la estela del "liberalismo conservador" de Aron: "Between two rights: Julien Freund and the origins of political realism in France", Patterns of Prejudice 48/3, 2014, pp. 248-264; luego, "Plettenburg not Paris: Julien Freund, the New Right, and France's Liberal Moment", en S. Sawyer \& I. Stewart (eds.), In Search of the Liberal Moment. Democracy, Anti-totalitarianism, and Intellectual Politics in France since 1950, Palgrave Macmillan US, 
guerra es pensar también el enemigo", y éste no se deja reducir al adversario en una competición cualquiera, sin violencia, en el sentido aquél que antes citábamos de Jouvenel.

En este punto se esconde acaso lo más nuclear del maquiavelismo de Freund, que le sitúa en la línea que en los últimos años C. Gambescia y J. Molina, sobre todo, han caracterizado, incluyéndole entre sus máximos representantes, como "liberalismo triste", "árquico" u "ordoliberal" 28 . También "conservador", pero en el sentido "contrautópico" o "contrarrevolucionario" que describe Alessandro Campi ${ }^{29}$, más que en el "moderado" o "insatisfecho" de S. de la Touanne o P.-A. Taguieff ${ }^{30}$, y desde luego que muy lejos de ese otro liberalismo ridens — según la magnífica tipificación también de Gambescia-, despolitizado y neutral, que no es en realidad sino otra versión del pensamiento mágico. Su apuesta por la mesocracia, partidario de un gobierno "mesurado, de poderes compartidos [...], que respeta la especificidad de las diversas actividades humanas [...] sin subordinarlas al arbitrio político" ${ }^{31}$, y que se opone por igual a la hipercracia de ciertas tendencias y

2016, pp. 39-59. En realidad, todo depende de que se admita o no una acepción política de liberalismo que rebase las categorías intelectuales generadas por los procesos revolucionarios del XVIII, como apunta el propio Freund en "La pensée libérale", Kwartaalschrift Wetenschappelijk Onderwijs Limburg 5/4, 1975, pp. 405-421. Desde el punto de vista de la historia de las doctrinas políticas, este liberalismo tiende a coincidir con la tradición del realismo europeo en forma de paleo o protoliberalismo, en la línea trazada por D. Negro en La tradición liberal y el Estado, Madrid, Unión Editorial, 1995 o, más recientemente, La tradición de la libertad, Madrid, Unión Editorial, 2019.

${ }^{28}$ C. Gambescia, Liberalismo triste. Un recorrido de Burke a Berlin, op. cit.; J. Molina, "Julien Freund, del realismo político al maquiavelianismo", Anales. 2004, Fac. de Ciencias Sociales / U.C.L.P., 2004, pp. 11-24; "Los cacicatos de la inteligencia. El Julien Freund de Pierre-André Taguieff”, Razón Española 157, 2009, pp. 195-202. Se trata, en la clasificación de Gambescia, de una de las cuatro modulaciones posibles de un tipo ideal, junto a otras de tipo macro, micro y, en su extremo conceptual, anárquico. Se integraría Freund en la línea que lleva desde Burke y Tocqueville a Pareto, Mosca, Ferrero, Croce, nuestro Ortega, Oakeshott, R. Aron o Isaiah Berlin, sobre la base del reconocimiento de unas constantes objetivas en los fenómenos políticos y, en especial, el poder, al que no siempre le es dado elegir medios ni objetivos.

${ }^{29}$ A. Campi, "Per una fenomenologia del Politico: introduzione al pensiero de Julien Freund", en J. Freund, La crisi dello Stato tra decisione e norma, Nápoles, Guida, 2008, p. 287; "Vista de conjunto sobre Julien Freund", Empresas Políticas 5, 2004, p. 115.

${ }^{30}$ Cf. S. de la Touanne, Julien Freund, penseur "machiavélien” de la politique, París, L'Harmattan, 2004, pp. 201 ss, 267-269, 313-321; P.-A. Taguieff, Julien Freund. Au coeur du politique, París, La Table Ronde, 2008, pp. 121-131.

31 J. Freund, "La crisis del Estado", Revista Política (Santiago de Chile) 1, 1982, p. 23. Cfr. "Lo Stato e le organizzazioni subordinate", en VV.AA., Linee per uno Stato moderno (III Incontro Romano della Fondazione G. Volpe), Roma, Volpe, 1976, p. 46; Le Nouvel 
al talante anárquico de otras, hay que entenderla a la luz de las dificultades a que siempre se expone la conjunción histórica de la libertad y el orden ${ }^{32}$. Esta postura, si aleja a Freund de la simple "política de potencia", en el sentido usual de la Machtpolitische, lo hace también de ese otro liberalismo hoy más frecuente que, engendrado por las categorías espirituales del Estado, vuelve empero contra él al trasladar toda libertad posible a espacios previamente despolitizados y presuntamente neutros, especialmente a la economía y la técnica. Por el contrario, si lo liberal puede converger con el realismo, en tanto que punto de vista específico sobre la pesanteur de la política, es principalmente en el sentido estratégico de una "dietética del poder", como dice Portinaro ${ }^{33}$, o de una "contrautopía conservadora", según Campi ${ }^{34}$, es decir: como una crítica desde la política al pensamiento utópico.

\section{3. ¿Weber o Aristóteles? Una lectura clasicista del realismo político}

$\mathrm{Al}$ entrar en los entresijos de la teoría política freundeana, se ha hecho común entre los investigadores detenerse predominantemente en dos de los tres pares de conceptos que él mismo fijó como sus "presupuestos", esto es, las condiciones que trazan de forma constante el ejercicio específico de alguna actividad. Esos dos presupuestos suelen ser o bien el schmittiano amigo/enemigo, del que emerge como su campo propio de acción la lucha (presupuesto “antropológico", lo califica Jean-Vincent Holeindre ${ }^{35}$ ), o bien

Âge. Éléments pour une théorie de la démocratie et de la paix, París, Rivière, 1970, pp. 7677; "La mésocratie", Critère 22, 1978, pp. 31-46; Politique et impolitique, op. cit., pp. 201210. Sobre la mésocratie como reverso normativo del démocratisme o democracia moral, algo se apunta en J. C. Valderrama, "Julien Freund, analista político: contextos y perspectivas de interpretación”, en P. Sánchez \& C. Martínez-Sicluna (eds.), Miradas liberales. Análisis politico en la Europa del s. XX, Madrid, Biblioteca Nueva, 2014, pp. 99-127; y "Agón y polémos. Polemocentrismo analítico y prioridad práctica de la amistad en el pensamiento político de Julien Freund", Contrastes. Revista Internacional de Filosofía 22, 1 (2017), pp. 119-136, si bien constituye una cuestión todavía abierta, precisamente en confrontación con el sentido político de su liberalismo, cuyo trasfondo "elitista" ha examinado recientemente D. Rosenberg, Anatomy of Eminence: French Liberalism and the Question of Elites, Walter de Gruyter GmbH, Berlín, 2020, p. 155 ss.

32 J. Freund, El gobierno representativo, Madrid, Encuentro, 2017, p. 118 ss.

${ }^{33}$ P.-P. Portinaro, El realismo político, op. cit., p. 87.

${ }^{34}$ A. Campi, "Vista de conjunto sobre Julien Freund", op. cit., p. 115; J.-V. Holeindre, "De la guerre au conflit. Sur l'œuvre polémologique de Julien Freund”, en G. Delannoi (et al.), Julien Freund, la dynamique des conflits, París, Berg International, 2011, pp. 54-64.

${ }^{35} \mathrm{~J}$.-V. Holeindre, "De la guerre au conflit. Sur l'œuvre polémologique de Julien Freund”, op. cit., p. 61. 
el weberiano mando/obediencia ("conservador"), que se refiere al orden. Atrás suele quedar un tercero, en este caso aroniano o, siguiendo con la caracterización de Holeindre, que está llena de sentido, "liberal" ${ }^{36}$ : el par público/privado, cuyo dominio específico es la opinión — pública, se entiende-, tomada no en su acepción teórica, sino en la práctica de ciertas certidumbres compartidas ${ }^{37}$.

De esta preferencia por un presupuesto u otro resulta una lectura de la teoría freundeana necesariamente oscilante entre dos extremos, y en consecuencia igualmente parcial: en un caso, el primero, principalmente conflictualista, aunque no lo sea en exclusiva, y en el otro - también principalmente- decisionista, dependiendo de cuál de ellos en concreto se sitúe en el vértice y atraiga cabe sí a los demás. Ahora bien, en la decantación histórica de estos presupuestos, sobre todo en los últimos años de redacción de L'essence du politique, a Freund se le fue haciendo cada vez más claro: $1^{\circ}$.- que en esa tríada no es el correspondiente a la lucha el que habría de ocupar el centro de gravedad de lo político, ni tampoco el relativo al orden, en la línea de la Herrschaftssoziologie de Weber, sino precisamente el otro reservado a la opinión o, si se prefiere, al régimen, como mediación en las relaciones tanto de uno como de otro presupuesto (público-privado) ${ }^{38}$; y $2^{\circ}$.- que en todo caso el interés de esta estructura descansa no en cada elemento tomado aisladamente, sino en su solidaridad o correlación orgánica ${ }^{39}$, por la que cada uno está llamado a informar perfiles diferenciados de la que en realidad es una misma y sola finalidad, bien sea que afecte

36 Fue el propio Freund quien declaró esa triple génesis — schmittiana, weberiana y aroniana- de sus presupuestos: P. Tommissen, "Julien Freund y Carl Schmitt. Algunos elementos para una reconstrucción de su amistad”, Empresas Políticas 5, 2004, pp. 117-124.

${ }^{37}$ Cfr. Aristóteles, Ét. Nic., VII, 1, 1145 b 4. Se trata de la "convergencia en las apreciaciones" u "opinión preponderante y relativamente estable [...] sobre la manera de concebir la situación [...] y el desarrollo de la unidad política como colectividad particular" (L'essence du politique, op. cit., p. 392), cuyo fundamento no es tanto el juicio autónomo de los individuos, cuanto - y esto es lo socialmente relevante- "la comunidad de juicio que reflejan las diversas asociaciones privadas [...] a las que pertenecen” (p. 396). La versión española de S. Nöel (1968 / 2018) traduce aquí “communauté de vue" por "unanimidad de criterio” (p. 497 en la ed. de 1968, Editora Nacional; p. 438 ed. 2018), lo que se abre a cierta confusión. De hecho, “[o]n ne saurait confondre opinion publique et unanimité”, escribe Freund poco antes (p. 394). Tratándose de un problema práctico, que no teórico, y dado que no presupone una unanimidad de convicciones en la evaluación de los proyectos que dan forma a la acción respecto de lo común, es preferible el uso de "comunidad de juicio".

${ }^{38}$ J. Freund, L'essence du politique, op. cit., pp. 5-6; P. Tommissen, "Julien Freund y Carl Schmitt. Algunos elementos para la reconstrucción de su amistad”, op. cit., pp. 118-120.

${ }^{39}$ Ibidem, pp. 304, 338. 
principalmente a la constitución del orden público (primer presupuesto: "commandement et obéissance font qu'il y a politique" ${ }^{40}$ ), a su organización interior (segundo presupuesto que es, así, central: "la relation du privé et du public détermine le domaine du politique" ${ }^{41}$ ); o a su protección en el escenario existencialmente conflictual en el que, quiérase o no, se mueve siempre la política (tercero de los presupuestos: “il n'y a de politique que là où il y a un ennemi réel ou virtuel" ${ }^{2}$ ). Por eso, para el análisis político no se trata tanto de tomar el conjunto de sus presupuestos, cuanto de tomarlos conjuntamente, o sea: desde la interdependencia por la que los tres se integran solidariamente en un mismo sistema de condicionamiento mutuo.

Si esto es así, hay que revisar entonces la prioridad que en ocasiones se asigna a alguno de ellos separadamente, con el resultado de acabar oscureciendo, más o menos según los casos, tanto el verdadero problema práctico supuesto en la función social de la política —que solo puede resolverse teniendo en cuenta sus fines, es decir: en clave estrictamente teleológica-, como su significación moral más allá de sus implicaciones estratégicas. Lo cual tiene importancia, porque obliga a enfrentar el pensamiento político de Freund, y el sentido también de su realismo, a una alternativa que representa en muy buena medida la piedra de toque que permite a un autor adscribirse o no precisamente a tal enfoque: ¿Weber o Aristóteles?

Nada que ver con esa caricatura que dibujan algunos de un realismo sin moral, obsesionado con los simples medios. Lo que se opone a una "política moral" no es el cinismo ni la amoralidad, sino una "moral de la política" capaz de dar cuenta y razón de sus propias leyes. Para endosarle a Freund penosas críticas en esa dirección, no ha hecho falta por lo general más que leerle en diagonal, pellizcando algunas páginas aquí y allá, sobre todo en La esencia de lo político. Probablemente poco —incluso nada- más. Solo así se entienden algunos reproches, como que reduzca el poder a la "dominación del hombre sobre el hombre" sin cabida para el compromiso o la negociación ${ }^{43}$; o que su adscripción a una determinada estirpe, para determinar la cual bastaría mirar el índice onomástico de L'essence du politique — “donde Maquiavelo, Hobbes, Weber, Carl Schmitt y Raymond

${ }^{40}$ Ibidem, p. 104.

${ }^{41}$ Ibidem, p. 280.

${ }^{42}$ Ibidem, p. 448; "La passion de la politique", op. cit., pp. 61-62.

${ }^{43}$ J.-W. Lapierre, "Quintessence du politique”, Esprit 36/9, 1968, p. 225. En buena medida también Alain Cambier: "Les limites de l'essentialisme politique: regard critique sur la philosophie politique de Julien Freund", en N. El Haggar \& J.-F. Rey (eds.), Politique et responsabilité. Enjeux partagés, París, L'Harmattan, 2003, p. 118 ss. 
Aron figuran entre los más citados" ${ }^{44}$, explicaría "su relativismo [?], su agudo sentido de la realidad y capacidad de traducción en conceptos simples y convencionales, una fuerte inclinación en favor del individuo, todo ello mezclado con un cierto pesimismo sobre el hombre y su destino", como hace años escribió François Chevrette.

\section{El tópico de un Freund decisionista}

La imagen del Freund decisionista, aunque explicable por cómo subrayaba él mismo la condición monocrática de cualquier poder - "la monocracia es consustancial al mando" ${ }^{45}$, dijo-, constituye sin embargo una visión demasiado estrecha de su teoría sobre el mando. Una visión estrecha que mantiene no solo quien decide extremar ese supuesto trasfondo decisionista, que es lo más frecuente, sino también quien pide su moderación externa mediante la intervención de otros factores tomados por políticos solo por su relación con el presupuesto aquél.

El primero olvida que "arbitrio" no es "arbitrariedad", y que afirmar, como Freund afirma, que saber y poder no se conmensuran ni se conjugan tampoco como los tiempos de un verbo ${ }^{46}$, en modo alguno es suponer a la voluntad privada de toda medida racional, sino solo de una puramente intelectual que encomendase a un acto de la voluntad — la decisión- el proceso táctico de volcar en el plano histórico verdades generadas al margen de la acción, aunque tuviesen alguna relación extrínseca con ella. Entraña ésta de la ideología y del pensamiento tecnocrático, dista mucho del uso práctico

${ }^{44}$ F. Chevrette, “À la recherche de l'essence du phénomène politique”, Canadian Journal of Political Science 2, 1969, p. 264. Un criterio, por cierto, de lo más caprichoso: de esos autores el índice incluye aún menos referencias que de Aristóteles, Platón, Kant, Proudhon, Marx o Rousseau, de encaje problemático en ese mismo esquema.

${ }^{45} \mathrm{~J}$. Freund, L'essence du politique, op. cit., p. 132. Sin contar, claro está, su filiación schmittiana, que es indudable, pero en la que aquí no cabe entrar. En todo caso, la óptica teórica del "konkretes Ordnungsdenken" desarrollado por Schmitt en Über die drei Arten des rechtswissenschaftlichen Denkens (1934), aunque avanzado en la segunda edición de Politische Theologie (1933), a propósito del pensamiento jurídico institucional, templa esa posible tendencia al decisionismo que caracterizaba al soberano frente al normativismo jurídico en Der Begriff des Politischen, que no tiene —como tampoco en Freund- el carácter arbitrario que en ocasiones se le asigna. Al respecto, "Vue d'ensemble sur l'œuvre de Carl Schmitt”, Revue européenne des sciences sociales 44, 1978, pp. 19-21, 33; L'essence du politique, op. cit., pp. 644-645.

${ }^{46}$ J. Freund, L'essence du politique, op. cit., p. 14; "La surenchère morale en politique", op. cit., p. 57. 
de razón que se da —sí- para la acción, pero no desde fuera de ella, sino en ella. La razón, una y la misma, se usa en ambos casos diferentemente: sea que se dirija a lo que es y así se nos impone necesariamente (pensamiento), o a lo que se quiere entre más o menos alternativas que en efecto sea (campo este propio de la acción).

En cuanto al segundo, el problema es que parte de una noción en realidad despolitizada del poder, puramente sociológica y "amorfa", como diría Weber, o "difusa" según Freund ${ }^{47}$, cuya significación política derivaría no tanto de su propia naturaleza, que le faculta para el logro de un tipo específico de fines, cuanto de los medios que tuviera a su disposición dentro de alguna forma de asociación, política o no, para el logro de cualesquiera fines. Políticamente, en cambio, no es así, ya que no es el Estado el que hace político al poder, sino el poder, más bien, el que hace Estado. No es el producto de una asociación, sino justamente al contrario, su condición. Y no de un modo amorfo, sino específico: precisamente como tal poder político, lo cual, en última instancia, significa público. "Público" y "privado" constituyen como su anverso y envés el estatuto del poder político, que lo es solo en lo público o con referencia a él. Por eso, si la dialéctica de lo privado y lo público limita el ejercicio del poder —como sostiene, p. e., Sébastien de la Touanne, a propósito de lo que él llama la "concepción maquiaveliana y decisionista de la politología freundeana" 48 , no es porque ese presupuesto ponga coto externamente a la tendencia de cualquier poder hacia su extremo, sino porque lo informa internamente en el sentido de que lo politiza. Es decir: porque lo ordena como un factor consustancial (y por eso mismo, como un factor no externo) a su propia definición en tanto que "poder político". De este modo, antes de que lo privado limite la acción del poder como desde fuera, desde el ángulo de lo no-político, éste ya se autolimita al ordenarse como tal poder político a su fin propio y específico.

Es verdad que lo privado impone un límite a las expresiones del poder en el espacio público. La cuestión es si puede tomarse como verdaderamente externa a él esa tal limitación, porque en tal caso tan político sería el poder en mesocracia - régimen de la mesura y equilibrio de poderes contrapuestos- como en sus extremos hiper o hipocráticos, o simplemente anárquicos, según la tipología que Freund desgrana en su "Breve ensayo sobre la

${ }^{47}$ M. Weber, Economía y sociedad. Esbozo de sociología comprensiva, México, F.C.E., 1984, p. 43, 699; J. Freund, L'essence du politique, op. cit., p. 258.

48 S. de la Touanne, Julien Freund, penseur "machiavélien" de la politique, op. cit., p. $132,137$. 
clasificación de los regímenes políticos” $(1968)^{49}$. Desde luego, el francés es explícito al respecto; el poder político se halla internamente autolimitado por el reconocimiento social que presupone, y eso significa que su extralimitación equivale ipso facto a su despolitización: no el colmo de su realización, pues, sino todo lo contrario, su desnaturalización. "Toda sobrepolitización - escribe- es una despolitización" ${ }^{50}$. Hacer de lo no-político el factor de su limitación supondría fijar la razón de su politicidad no en sí mismo, sino en otra parte; sobre todo en el orden de los medios, y aún más concretamente en la disposición y el uso de la fuerza. Es la lectura de Sébastien de la Touanne, Alain Cambier y, antes, G. Sartori o Norberto Bobbio, para quienes decisionismo y polemocentrismo son en realidad secuelas lógicamente dependientes de una misma visión unilateral de la política basada fundamentalmente en dos supuestos: a) una lectura en clave weberiana (Herrschaft) del "mando" político (commandement); y b) la reducción de "lo político", definido desde la excepción, al monopolio de la fuerza. De la combinación de ambos factores resultaría en buena lógica la tendencia a confundir el orden de los fines con el estratégico de los solos medios, y así, el sentido general del "orden público" — para Freund un orden específico de acción- con la sola efectividad de los poderes del Estado ${ }^{51}$.

${ }^{49} \mathrm{~J}$. Freund, El gobierno representativo, Madrid, Encuentro, 2017, pp. 99-140.

${ }^{50}$ Ibidem, p. 120.

${ }^{51}$ Por eso, según Bobbio, "la definición de política en términos de amigo-enemigo no es de ninguna manera incompatible con la que [...] hace referencia al monopolio de la fuerza. No solo no es incompatible, sino que es una especificación y por lo tanto, en último análisis, una confirmación. En cuanto el poder político se distingue por el instrumento que utiliza para alcanzar los propios fines, y este instrumento es la fuerza física, éste es el poder al cual se recurre para resolver los conflictos que si no se resolvieran provocarían la disgregación del Estado y del orden internacional, y son justamente los conflictos en los cuales, ubicándose los contendientes uno frente al otro como enemigos, la vita mea es la mors tua", N. Bobbio, Teoría General de la Política, Madrid, Trotta, 2005, pp. 186-188.

${ }^{52}$ Así, v. gr., A. Passerin d'Entrèves: “[...] since for them [= machiavellians] the essence of politics consisted in the dominance of a minority over a majority, that is, in a relation of force. It still more recent days, a theory has been advanced according to which the basic "category" of politics is to be found in the antinomy of friend and enemy (Freund/Feind), in the group solidarity which is brought about by the challenge of the menace of an opponent. This theory was put forward some thirty years ago by a nazi writer (Carl Schmitt) [!]. It has been recently revived by two political philosophers, one French (Julien Freund), the other Italian (Sergio Cotta). Here again the task of political philosophy is seen as consisting in determining the "essence" of politics, and that essence is brought back, ultimately, to an expression of force", "On the notion of political philosophy", en K. Beyme (ed.), Theory and Politics - Theorie und Politik. Festschrift zum 70. Geburtstag für Carl Joachim Friedrich, La Haya, Springer Verlag, 1971, pp. 305-306. Cf. G. Sartori, Elementi di Teoria Politica, Bo- 
Aquí suele radicar lo nuclear de muchas de las objeciones demonizadoras del realismo, al que achacan sus críticos una hipertrofia de los medios sobre el valor de los fines ${ }^{52}$. Sin embargo, tampoco la politicidad de la fuerza descansa en las limitaciones que permitieran domesticarla haciéndola socialmente tolerable, sino en el contexto práctico en el que ella se integra y define como tal medio "político", y por referencia a cuyo fin justamente se constituye en "medio". No es la simple capacidad de uso de la fuerza lo que hace del poder un "poder político": ese carácter se lo dan sus fines, y en consecuencia, el espacio práctico donde tales fines son posibles. Solo secundariamente politeia es policía; antes describe un orden específico de acción, esto es: un ethos ${ }^{53}$.

Entre una y otra imagen, la del Freund conflictualista y el decisionista, quien se nos pierde en realidad es el verdadero Freund, que es - si lo queremos entender así- el publicista. O el político, porque político es precisamente no subrayar alguno de los presupuestos, sino tomarlos juntos a los tres. Y esto exige mirar la política desde un ángulo que no es el habitual en esos otros dos casos, ya que obliga a tomar como lo primero no las causas ni los medios, no el poder, en un sentido exclusivamente cratológico, sino los fines.

\section{De los medios al fin de la política}

\subsection{No uno, sino tres principios de la acción política}

El presupuesto de mando y obediencia cumple evidentemente un papel primordial en la articulación de la unidad social. Se trata, escribe Freund, de "la relación que hace ser a la política" ${ }^{4}$, y en consecuencia, por su alcance, que hace ser la sociedad como unidad política. Pero ni la sociedad se agota en ser política, ni tampoco en ser político se agota el individuo. Ambos pueden asumir otras muchas determinaciones. Testigos y garantes de ello son los otros presupuestos, relativos no a la realidad in genere de lo político, como el anterior, sino al orden de sus fines: la organización de la colectividad y su defensa contra las colectividades exteriores ${ }^{55}$. Se entiende

logna, Il Mulino, 1995, p. 286 ss; N. Bobbio, Teoría General de la Politica, op. cit., p. 180, 188 ss, 1218; J.-W. Lapierre, “Quintessence du politique”, op. cit., p. 225.

${ }_{53}$ Cf. N. Bobbio, N. Matteucci \& G. Pasquino, Diccionario de Política, Buenos Aires, Siglo XXI, 2007, p. 556 ss.

${ }_{54}^{54}$ J. Freund, L'essence du politique, op. cit., p. 107.

${ }^{55}$ Cfr. Ibidem, p. 96. 
entonces por qué no es posible para Freund adentrarse en la condición política de la vida social sin tener antes en cuenta la intercompenetración orgánica de sus presupuestos y sin advertir, por tanto, su interdependencia práctica, en tanto que la realización de unos impone una medida al desarrollo de los otros. En efecto, dice, "no es posible captar la esencia de lo político limitando las investigaciones a una sola de estas tres categorías [...] hay entre ellos una correlación de orden sustancial, es decir: en ausencia de uno u otro, una determinada actividad deja de ser política. [...] De modo que son los tres presupuestos juntos los que determinan la esencia de lo político, no separadamente" ${ }^{56}$. Hay entre ellos una solidarités7 o unidad orgánica que además explica la estructura formal de su finalidad, por cuanto los objetivos de cada uno de ellos (constitución, organización, protección) los integra como modulaciones diferenciadas de un mismo bien -el bien común- en muy buena medida poliédrico ${ }^{58}$.

De todos modos, que los tres presupuestos gocen de la misma importancia en el plano puramente analítico ${ }^{59}$, no significa que en la perspectiva práctica que impone el punto de vista de los fines todos asuman igual centralidad. Es cierto que no hay "orden" más que por referencia al mando, y también lo es, por otra parte, que el par ami-ennemi aletea en el entero campo del existir político, no habiendo política sin conflictividad. Pero en la tríada freundeana es el segundo presupuesto - no el primero ni el tercero- el que cobra una especial centralidad, por tres razones al menos: a) por determinar la condición verdaderamente política de los otros dos, identificando por tanto las formas distintivamente políticas de poder y hostilidad; $b$ ) por fundar el significado específico de la libertad política, relativa precisamente a los asuntos públicos; y $c$ ) por dar contenido y posibilidad al bien común. Ciertamente, si las relaciones de autoridad determinan el alcance y significado del orden, la delimitación histórica de lo privado y público el de las libertades (en plural). Orden y libertad son categorías consustanciales a la política, y por la diversidad de sus fórmulas de articulación varían los regímenes. Por eso, la constitución política de una sociedad no se dirige solo a la consolidación de su orden, sino a la definición también de los sentidos y límites de la libertad, puesto que al constituirse un pueblo, es la morfología de su ciudadanía lo que se constituye: "Un régimen —escribe

${ }^{56}$ Ibidem, p. 304.

${ }^{57}$ Ibidem, p. 338.

${ }^{58}$ Cfr. J. C. Valderrama, “Agón y polémos. Polemocentrismo analítico y prioridad práctica de la amistad en el pensamiento político de Julien Freund", op. cit., p. 126 y ss.

${ }^{59}$ J. Freund, L'essence du politique, op. cit., p. 322. 
Freund— no se caracteriza únicamente por su constitución —ésta no es más que su expresión jurídica- sino que comporta otros aspectos, en particular una concepción del mundo, a la que representa, y un estilo de vida que impone limitando o no, por ejemplo, la libertad de los individuos y de sus asociaciones" ${ }^{60}$. Desde este punto de vista, la defensa de la forma mesocrática, sobre la base de la antigua poliarquía, lejos de tratarse para Freund de una simple toma de partido personal, refleja — como para cada ethos su régimen - la expresión natural misma de lo político, la más adecuada a lo que entendemos como el constitutivo formal de nuestra propia tradición histórico-política.

\subsection{La posición axial del par público-privado}

Freund, que hasta poco antes de su tesis mantuvo este segundo presupuesto en primera posición, anterior al duplo mando-obediencia, con su posterior deslizamiento a una segunda vino a subrayar esa peculiar función axial que asume en efecto respecto de los otros dos, al configurar el ethos en el interior del cual - y solo en el interior del cual — las otras relaciones adquieren significación política. Piet Tommissen ${ }^{61}$ dio a conocer hace ya unos años al público español un plan de trabajo fechado en octubre de 1959 - año en que se iniciaron sus relaciones con Aron y Schmitt ${ }^{62}$ - en el que Freund comunicaba a Aron, recién estrenado su papel de director de tesis, la relación de presupuestos en un orden distinto, donde la dialéctica público-privado figuraba antes de las otras dos. Así se mantendría por bastante tiempo, hasta comienzos de 1964, momento en el que fijaría el orden que conocemos desde entonces.

La segunda posición que este presupuesto ocupa a partir de ese momento no responde a una postergación de su valor. Su centralidad cobra aquí

${ }^{60}$ J. Freund, El gobierno representativo, op. cit., p. 70, 130. En efecto, “[u]ne constitution n'est pas exclusivement politique, elle définit l'ordre social, dans le respect des libertés non politiques. L'artiste est libre comme artiste, le chercheur comme chercheur, parce qu'il leur appartient et non au politique de déterminer les normes de l'art et de la science. Ils cessent d'être libres dès qu'on les soumet à la volonté hégémonique d'un pouvoir politique qui ne reconnaît plus les limites qu'impose la reconnaissance d'une société civile. Celle-ci est la solution relativement la meilleure que les Modernes ont trouvée pour concilier les impératifs de l'ordre et les aspirations de la liberté", "Préface" a C. Delsol, Essai sur le pouvoir occidental, París, P.U.F., 1985, p. 13.

${ }^{61}$ P. Tommissen, "Julien Freund y Carl Schmitt. Algunos elementos para la reconstrucción de su amistad”, op. cit., pp. 117-124.

${ }^{62}$ Vid. J. C. Valderrama, "Julien Freund, teórico de las esencias: un intento filosófico de clarificación”, Res Publica. Revista de Historia de las Ideas Políticas 22/2, 2019, pp. 461-476. 
tintes geométricos, que no axiológicos, como el vértice al que se orientan los otros y que determina —cualificándola- su realización práctica. Relativo a la organización interna de la sociedad, es él el que permite discriminar cuál es el espacio en que se cumple lo político, cuál el de las demás "esencias" y qué tipo de vínculos los ligan entre sí. Por eso, aunque mando y obediencia hacen posible la política, es la relación de lo público y privado la que permite deslindar lo político de otras posibilidades sociales de ordenación, permitiendo identificar al mismo tiempo determinadas relaciones de poder y hostilidad como formas específicamente políticas (o no) de darse.

El problema entonces de nuestra existencia política trasciende para Freund con mucho las simples relaciones de influencia que podrían ejercerse en el interior de una organización social. Dando eso por supuesto, lo decisivo se encuentra en otra parte: en la posibilidad misma de participar socialmente de aquellos fines por referencia a los cuales esas mismas relaciones adoptan su condición política. Esta posibilidad presupone una previa discriminación de espacios donde bienes de tal naturaleza puedan formularse y perseguirse: el "orden público" 63 .

\section{Conclusión}

Testigo de las constantes de nuestra existencia histórica, el realismo político configura antes un ánimo que una doctrina, una tradición homogénea de pensamiento o un saber autónomo en el campo del conocimiento político. Freund quiso compendiarlas todas en su adopción, si se quiere, aristotelizante — baste clásica- del prisma maquiaveliano, en cuya fórmula fijó su adscripción a este modo de ser realista, lejos de su reducción dominiocéntrica, esencialmente cratológica. Pues subrayar la importancia del poder en política, o incluso de la fuerza y la astucia, no va en contra del protagonismo práctico, pero igualmente analítico o fenomenológico, del orden de los fines, sino que solo se opone a su quintaesenciación intelectualista, tal y como se da en la génesis de esa deformación de la "morale de la politique" que es, para el lorenés, el moralismo político.

Es importante - creo- insistir en ello: los fines son primero. Para el análisis y en la acción. No se entendería, si no, la posición central que le reserva Freund al par público-privado en el catálogo de sus "presupuestos"; ni la prioridad tampoco de la amistad sobre la potencia que también

${ }^{63}$ J. Freund, L'essence du politique, op. cit., p. 292. 
él recuerda de manera explícita en L'essence du politique y otros lugares. "La finalidad política —escribe ahí- entendida como promoción del bien común exige indudablemente que se le otorgue prioridad a la amistad", con independencia de que ese bien "sea sin cesar objeto de discusiones, luchas y a menudo guerras, es decir, aunque sea siempre necesario superar en todas partes el obstáculo de la enemistad" ${ }^{64}$. Siendo así, no puede decirse que Freund reduzca la política a lo que sin duda constituye un aspecto suyo, elemental y básico, mas no único: survie, conservation, protection, ya que tal fin se halla inmediatamente inserto en un orden moral al servicio del desarrollo libre y multiforme de la individualidad, de acuerdo con la pluralidad de las "esencias". Este es, acaso, el punto de engarce inmediato de perspectivas a priori disonantes, aunque fuese solo a causa de la equivocidad de sus denominaciones (realismo y liberalismo políticos). En al menos cinco principios de raigambre clásica ${ }^{65}$ se alinea el realismo aquí a cierta vindicación liberal del equilibrio y la heterogeneidad de los fines humanos: (1) el reconocimiento de la autonomía de la política y de su relativa primacía histórica ${ }^{66} ;(2)$ la crítica al utopismo y desmitificación de las ideologías como clave hermenéutica de la experiencia política ${ }^{67}$; (3) la centralidad del poder - y así la decisión y la fuerza- en la articulación de los regímenes políticos ${ }^{68}$; y (4) el reconocimiento de la inevitabilidad de los conflictos, que

${ }^{64}$ Ibidem, p. 664, 554; cf. 449.

${ }^{65}$ Cf. P. Portinaro, "Sul realismo político: una sinossi", en A. Campi \& S. de Luca (comps.), Il realismo politico. Figure, concetti, prospettive di ricerca, op. cit., p. 16 ss.

${ }^{66}$ Vid. J. Molina, "Le primat du politique. El realismo político de Raymond Aron", Sociologia: Revista da Faculdade de Letras da Universidade do Porto, 16 (2006), 205-229.

${ }^{67}$ En especial, J. Freund, Utopie et violence, París, Rivière, 1978; "Das Utopische in den gegenwärtingen Ideologien”, en VV.AA., Säkularisation und Utopie. Ebrachen Studien, Ernst Forsthoff zum 65. Geburtstag, Stuttgart, Kohlhammer, 1967, pp. 95-118; "Le révolutionnarisme", Res Publica 11, 3 (1969), pp. 485-517; "Qu'est-ce que la politique idéologique?", Revue européenne des sciences sociales 17, 46 (1979), pp. 139-146; “Théorie et Utopie", Philosophie et Politique. Annales de l'Institut de Philosophie et des Sciences Morales de l'U.L.B. 2 (1980-81), pp. 11-22; "Les aspects eschatologiques de l'idéologie", L'Analyste (1983), pp. 55-61; M. Weyembergh, Entre politique et technique: aspects de l'utopisme contemporain, París, Vrin, 1991.

${ }^{68}$ Por eso, la idea "de una política sin poder no es más que una fantasía utópica, en el sentido peyorativo del término, porque sea cual sea el régimen, más arcaico o más evolucionado, más rudimentario o más complejo, más irracional o más racionalizado..., no existe y nunca existirá política sin poder. No solo hay cierta afinidad entre estas dos nociones; es que su relación es de una necesidad lógica. [...] Por consiguiente, mientras el hombre viva políticamente, mientras siga siendo lo que siempre ha sido en la historia, no podrá escapar a esta realidad del poder”, J. Freund, El gobierno representativo, op. cit., pp. 118-119. 
unido a (5) una visión realista de la naturaleza humana - no pesimista o trágica en su caso- confiere un pathos específico al sino del hombre políti$\mathrm{co}$, en liza permanente entre fortuna y virtù.

Instruido por la lectura de Aristóteles, Freund marcó pronto distancia de cualquier posible decisionismo que anclara unilateralmente su visión de la política en la experiencia del puro poder, tal y como se insinúa en las márgenes de un escenario antagonista. Que no es a sí propio a quien sirve el poder, sino al ethos: esa especial forma de vida que se constituye en lo público y que se le entrega al poder solo para custodiarla ${ }^{69}$.

\section{Bibliografía}

Bobbio, N., Teoría General de la Política. Madrid, Trotta, 2005.

Cambier, A., "Les limites de l'essentialisme politique: regard critique sur la philosophie politique de Julien Freund", en N. El Haggar \& J.-F. Rey (eds.), Politique et responsabilité. Enjeux partagés. París, L'Harmattan, 2003, 113-137.

Campi, A., "Vista de conjunto sobre Julien Freund", Empresas Politicas, 5 (2004), 113-116.

Campi, A., "Raymond Aron y la tradición del realismo político", en J. $\mathrm{M}^{\mathrm{a}}$ Lassalle (coord.), Raymond Aron. Un liberal resistente. Madrid, F.A.E.S., 2005, pp. 69-93.

Campi, A., "Per una fenomenologia del Politico: introduzione al pensiero de Julien Freund", en J. Freund, La crisi dello Stato tra decisione e norma. Nápoles, Guida, 2008.

Campi, A. \& de Luca, S. (comps.), Il realismo politico. Figure, concetti, prospettive di ricerca. Soveria Mannelli, Rubbettino, 2014.

Chevrette, F., "À la recherche de l'essence du phénomène politique”, Canadian Journal of Political Science, 2 (1969), 262-264.

Conde, F. J., El hombre, animal político. Madrid, Encuentro, 2011.

De Jouvenel, B., Teoría pura de la política. Madrid, Revista de Occidente, 1965. Delsol, C., Essai sur le pouvoir occidental. París, P.U.F., 1985.

Freund, J., "La passion de la politique", Foi et Vie, 61/2 (1962), 42-64.

Freund, J., "Chapelet de souvenirs", Bulletin de la Faculté des Lettres de Strasbourg, 47/1-2 (1968), 9-20.

${ }^{69}$ Vid. J. Freund, Politique et impolitique, op. cit., p. 287; J. C. Valderrama, “Agón y polémos. Polemocentrismo analítico y prioridad práctica de la amistad en el pensamiento político de Julien Freund”, op. cit., p. 133. 
Freund, J., Le Nouvel Âge. Éléments pour une théorie de la démocratie et de la paix. París, Rivière, 1970.

Freund, J., "La pensée libérale", Kwartaalschrift Wetenschappelijk Onderwijs Limburg 5, 4 (1975), pp. 405-421.

Freund, J., "Lo Stato e le organizzazioni subordinate", en VVAA, Linee per uno Stato moderno (III Incontro Romano della Fondazione G. Volpe). Roma, Volpe, 1976, pp. 23-47.

Freund, J., "La mésocratie", Critère, 22 (1978), 31-46.

Freund, J., "Vue d'ensemble sur l'œuvre de Carl Schmitt", Revue européenne des sciences sociales, 44 (1978), 7-38.

Freund, J., "Ébauche d'une autobiographie intellectuelle", Revue européenne des sciences sociales, 54-55 (1981), 7-47.

Freund, J., "La crisis del Estado", Revista Política (Santiago de Chile), 1 (1982), 9-29.

Freund, J., Sociologie du conflit. París, P.U.F., 1983.

Freund, J., Politique et impolitique. París, Sirey, 1987.

Freund, J., "La surenchère morale en politique", Actions et recherches sociales. Revue interuniversitaire de sciences et pratiques sociales, 28/3 (1987), 45-62.

Freund, J., "La politique politique", Tijdschift voor de studie van de verlichtine en van het Vrije Denken, 16/2-4 (1988), 197-212.

Freund, J., Philosophie philosophique. París, La Découverte, 1990.

Freund, J., "Entretien avec Julien Freund", Vouloir (1990), 61-62.

Freund, J., L'essence du politique. París, Dalloz, 2004 (1ª: 1965).

Freund, J., El gobierno representativo. Madrid, Encuentro, 2017.

Freund, J., La aventura de lo político. Madrid, Encuentro, 2019.

Gambescia, C., Liberalismo triste. Un recorrido de Burke a Berlin. Madrid, Encuentro, 2015.

Holeindre, J.-V., "De la guerre au conflit. Sur l'œuvre polémologique de Julien Freund", en G. Delannoi (et al.), Julien Freund, la dynamique des conflits. París, Berg International, 2011, pp. 54-64.

Lapierre, J.-W., "Quintessence du politique”, Esprit 36, 9 (1968), 200-228. Molina, J., "Julien Freund, del realismo político al maquiavelianismo", Anales. 2004, Fac. de Ciencias Sociales / Univ. Cat. de La Plata, 2004, pp. 11-24.

Molina, J., "Le primat du politique. El realismo político de Raymond Aron", Sociologia: Revista da Faculdade de Letras da Universidade do Porto 16 (2006), 205-229.

Molina, J., "Los cacicatos de la inteligencia. El Julien Freund de PierreAndré Taguieff”, Razón Española 157 (2009), 195-202. 
Molina, J., "Realismo político y crítica de las religiones seculares en Raymond Aron", en M. Herrero (ed.), Religion and the Political. Hildesheim, Olms Verlag, 2012, pp. 249-269.

Molina, J., "Sobre las formas límite del pensamiento político”, en L. Bueno Ochoa (coord.), Ismos y Política. Diálogos con Dalmacio Negro. Madrid, Universidad Complutense, 2013, pp. 137-157.

Molina, J., "Julien Freund o la imaginación del desastre", Nueva revista de politica, cultura y arte 158 (2016), 221-232.

Oro Tapia, L. R., El Concepto de Realismo Político. Santiago de Chile, Ril Edits., 2013.

Passerin d'Entrèves, A., "On the notion of political philosophy", en K. Beyme (ed.), Theory and Politics - Theorie und Politik. Festschrift zum 70.Geburtstag für Carl Joachim Friedrich. La Haya, Springer Verlag, 1971.

Portinaro, P. P., El realismo político. Buenos Aires, Nueva Visión, 2007.

Rosenberg, D., Anatomy of Eminence: French Liberalism and the Question of Elites. Walter de Gruyter GmbH, Berlín, 2020.

Sartori, G., Elementi di Teoria Politica. Bologna, Il Mulino, 1995.

Schmitt, C., Diálogo sobre el poder y el acceso al poderoso. Buenos Aires, F.C.E., 2010.

Schmitt, C., El concepto de lo político. Madrid, Alianza, 2019.

Taguieff, P.-A., Julien Freund. Au coeur du politique. París, La Table Ronde, 2008.

Tommissen, P., "Julien Freund y Carl Schmitt. Algunos elementos para la reconstrucción de su amistad", Empresas Politicas 5 (2004), 117-124.

Touanne, S. de la, Julien Freund, penseur "machiavélien" de la politique. París, L'Harmattan, 2004.

Valderrama Abenza, J. C., "Julien Freund, analista político: contextos y perspectivas de interpretación”, en P. Sánchez \& C. Martínez-Sicluna (eds.), Miradas liberales. Análisis político en la Europa del s. XX. Madrid, Biblioteca Nueva, 2014, pp. 99-127.

Valderrama Abenza, J. C., “Agón y polémos. Polemocentrismo analítico y prioridad práctica de la amistad en el pensamiento político de Julien Freund”, Contrastes. Revista Internacional de Filosofía 22, 1 (2017), pp. 119-136.

Valderrama Abenza, J. C., "Julien Freund, teórico de las esencias: un intento filosófico de clarificación”, Res Publica. Revista de Historia de las Ideas Políticas 22, 2 (2019), pp. 461-476.

Weber, M., Economía y sociedad. Esbozo de sociología comprensiva. México, F.C.E., 1984. 